\title{
Clinical and Surgical Strategies for Avoiding or Reducing Allogeneic Blood Transfusions
}

\author{
Antonio Alceu dos Santos ${ }^{\mathrm{a}, \mathrm{d}}$, Jose Francisco Baumgratz ${ }^{\mathrm{b}}$, Jose Henrique Andrade Vila ${ }^{\mathrm{b}}$, \\ Rodrigo Moreira Castro ${ }^{\mathrm{c}}$, Rodrigo Freire Bezerra ${ }^{\mathrm{a}}$
}

\begin{abstract}
Blood transfusions have still been used as a standard therapy to treat severe anemia. Current evidences point to both excessive allogeneic blood consumption and decreased donations, which result in reduced stocks in blood banks. Several studies have increasingly suggested a more restrictive transfusion practice for blood products. Currently, a number of autologous blood conservation protocols in surgeries have been noted. We report a case of severe anemia with $2.9 \mathrm{~g} / \mathrm{dL}$ hemoglobin, which was successfully handled without using the standard therapy to treat anemia with hemotransfusions. Such a case of severe anemia condition resulted after the patient was submitted to ascending aortic aneurism repair, valvar aortic replacement, reimplantation of right coronary ostium, followed by a coronary artery bypass grafting and several postoperative complications. The main clinical and surgical strategies used in this case to avoid blood transfusions were acute normovolemic hemodilution, intraoperative blood cell salvage, and meticulous hemostasis, beyond epsilon-aminocaproic acid, desmopressin, prothrombin complex concentrate, human fibrinogen concentrate, factor VIIa recombinant, erythropoietin and hyperoxic ventilation.
\end{abstract}

Keywords: Cardiac surgical procedures; Blood transfusion; Blood preservation; Anemia; Bloodless medical procedures; Surgical procedures

\section{Introduction}

Since the 19th century, allogeneic blood transfusions have still

Manuscript accepted for publication April 05, 2016

${ }^{a}$ Hospital Beneficencia Portuguesa de Sao Paulo, Rua Maestro Cardim, 560, $2^{\circ}$ Andar, Sala 22, Bela Vista, Sao Paulo, SP, CEP: 01323-900, Brazil

${ }^{b}$ Hospital Beneficencia Portuguesa de Sao Paulo, Rua Maestro Cardim, 769, Bloco I, $2^{\circ}$ Andar, Sala 202, Bela Vista, Sao Paulo, SP, CEP: 01323-900, Brazil 'Hospital Beneficencia Portuguesa de Sao Paulo, Rua Martiniano de Carvalho, 864, Sala 1004, Bela Vista, Sao Paulo, SP, CEP: 01323-900, Brazil

${ }^{\mathrm{d} C}$ Corresponding Author: Antonio Alceu dos Santos, Hospital Beneficencia Portuguesa de Sao Paulo, Rua Maestro Cardim, 560, $2^{\circ}$ Andar, Sala 22, Bela Vista, Sao Paulo, SP, CEP: 01323-900, Brazil.

Email: antonioalceu@cardiol.br

doi: http://dx.doi.org/10.14740/cr463w been used as standard therapy for severe anemia. However, the level of patient's tolerance to the anemia that is considered by the physician is quite variable. In coronary artery bypass grafting $(\mathrm{CABG})$, the transfusion rate for red blood cells, plasma and platelets can vary from $0 \%$ to $97.5 \%$ in many hospitals [1]. In addition, there are studies showing a global reduction on blood donations, resulting in reduced stocks in blood banks [2]. This situation is real in many countries where the demand for allogeneic blood is growing at a larger intensity than the blood donations, pointing to a shortfall of blood products [3].

Since the 1980s, when it was discovered that HIV is transmitted by blood transfusions, several studies have been initiated to assess risks and benefits of allogeneic blood transfusions. The literature shows that this medical practice can result in higher mortality and morbidity [4-6], and higher hospital's length of stay and costs [5].

Studies have increasingly proposed a more restrictive conduct for blood transfusion in surgery, as well as the need of the management and conservation of the autologous blood [7]. Hospitals worldwide have sought to introduce several measures to ration the usage of allogeneic blood and this has become a hospital quality criterion pursued by health services quality certified agencies [8]. Several strategies have been proposed to alleviate blood products consumption in cardiac surgeries [9-11].

The aim of this case report is to demonstrate that through a multidisciplinary planning (surgeon, clinical physician, anesthesiologist, and physicians intensive care) with clinical and surgical strategies of autologous blood conservation, it was possible to avoid allogeneic blood transfusion in a patient with severe anemia, submitted to severe and complex heart surgery, and with various postoperative complications.

\section{Case Report}

The patient was a 25 -year-old man, $1.68 \mathrm{~m}$ high and $1.64 \mathrm{~m}^{2}$ of body surface, with chronic kidney failure requiring dialysis for focal segmental glomerulosclerosis (FSGS) since the age of 2. In 1997, he was submitted to the first kidney transplant. After 8 years, there was recurrence of FSGS with graft loss. In 2006, he was submitted to the second kidney transplant. But after 4 years, he resumed dialysis treatment due to new kidney failure.

Since then, he developed congestive heart failure due to degenerative aortic failure and hypervolemia. In 2012, he developed cardiac decompensation, progressing to functional 

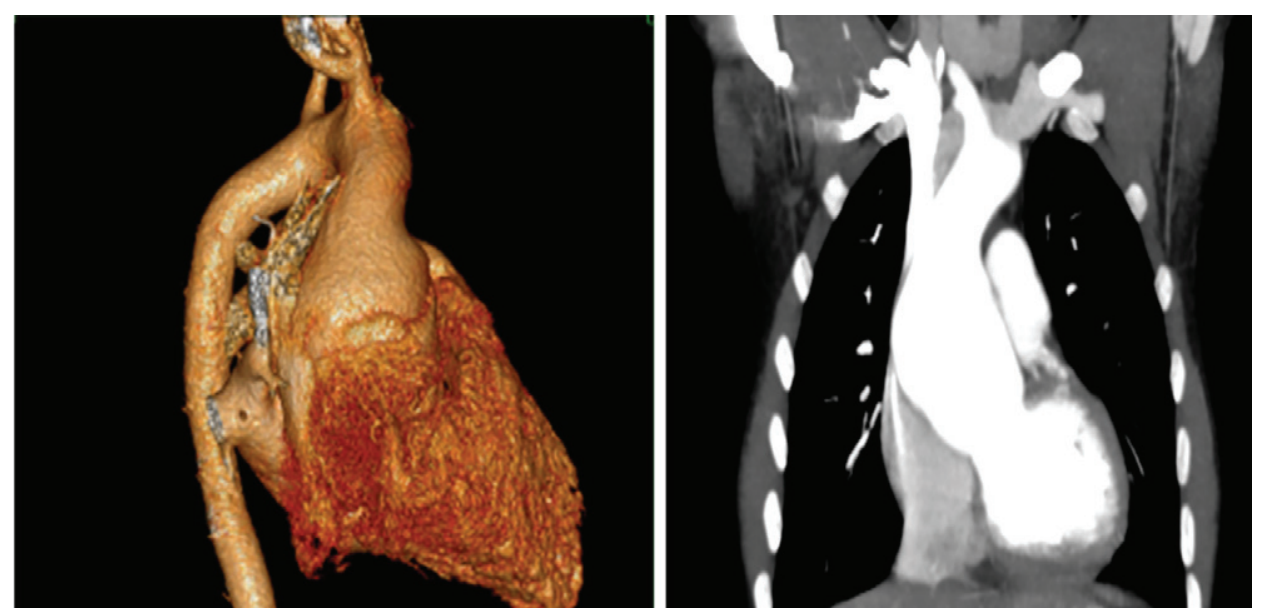

Figure 1. Computed angiotomography of thoracic aorta pre-surgery.

class IV of NYHA (New York Heart Association), despite of the optimized therapy. Doppler echocardiography showed left ventricular with an important cavity increase (LVDD: $73 \mathrm{~mm}$, LVSD: $58 \mathrm{~mm}$ ) and a moderate decrease in systolic function (LVEF: 39\% (Teichholz) and delta D: 20\%), major thoracic aorta root dilatation and aortic valve insufficiency also of important degree. The patient underwent computed angiotomography that confirmed major ascending thoracic aorta dilatation, measuring $7.2 \times 7.0 \mathrm{~cm}$ in its greatest transverse diameter (Fig. 1).

For his own reasons, the patient requested that the procedure was performed without the use of allogeneic blood transfusion. To meet patient's requirement, our team developed a multidisciplinary protocol that involved clinical and surgical strategies of autologous blood conservation and management in the pre-, intra- and postoperative periods.

Preoperatively, the optimization of the red cell mass was carried out through the use of ferric hydroxide saccharate, folic acid, vitamin B12 and recombinant human erythropoietin ( $\mathrm{r}$ $\mathrm{Hu}-\mathrm{EPO}$ ) at a dosage of $600 \mathrm{IU} / \mathrm{kg} /$ week (admission on January 07,2013 with hemoglobin $(\mathrm{Hb})$ of $17.5 \mathrm{~g} / \mathrm{dL}$ and platelets of $\left.134,000 / \mathrm{mm}^{3}\right)$.
He underwent surgery on January 08, 2013 for implantation of biologic aortic valve, aneurysm repair of ascending thoracic aorta using a synthetic graft, and reimplantation of right coronary ostium at the tube. Time of this first cardiopulmonary bypass (CPB) was $185 \mathrm{~min}$. Soon after, he presented asystole and major bleeding, requiring CPB for more $40 \mathrm{~min}$. Immediately after leaving this second $\mathrm{CPB}$, he progressed to another serious picture of arrhythmia (ventricular fibrillation) of difficult reversal. Due to hyperkalemia $(7.7 \mathrm{mEq} / \mathrm{L})$, emergency hemodialysis was performed. Still, he remained unstable with frequent episodes of ventricular fibrillation. For eliminating arrhythmia of ischemic etiology (insufficient blood flow to the myocardium by coronary ostia), CPB was again installed for another $90 \mathrm{~min}$ to perform CABG (anastomosis of aorta-right coronary bypass and aorta-left anterior descending coronary bypass), beyond another meticulous hemostasis for controlling excessive bleeding. The total CPB time for this surgery was $315 \mathrm{~min}$.

Intraoperatively, acute normovolemic hemodilution, blood cell salvage and meticulous hemostasis were used, beyond the epsilon aminocaproic acid, desmopressin, prothrombin complex concentrate, human fibrinogen concentrate and
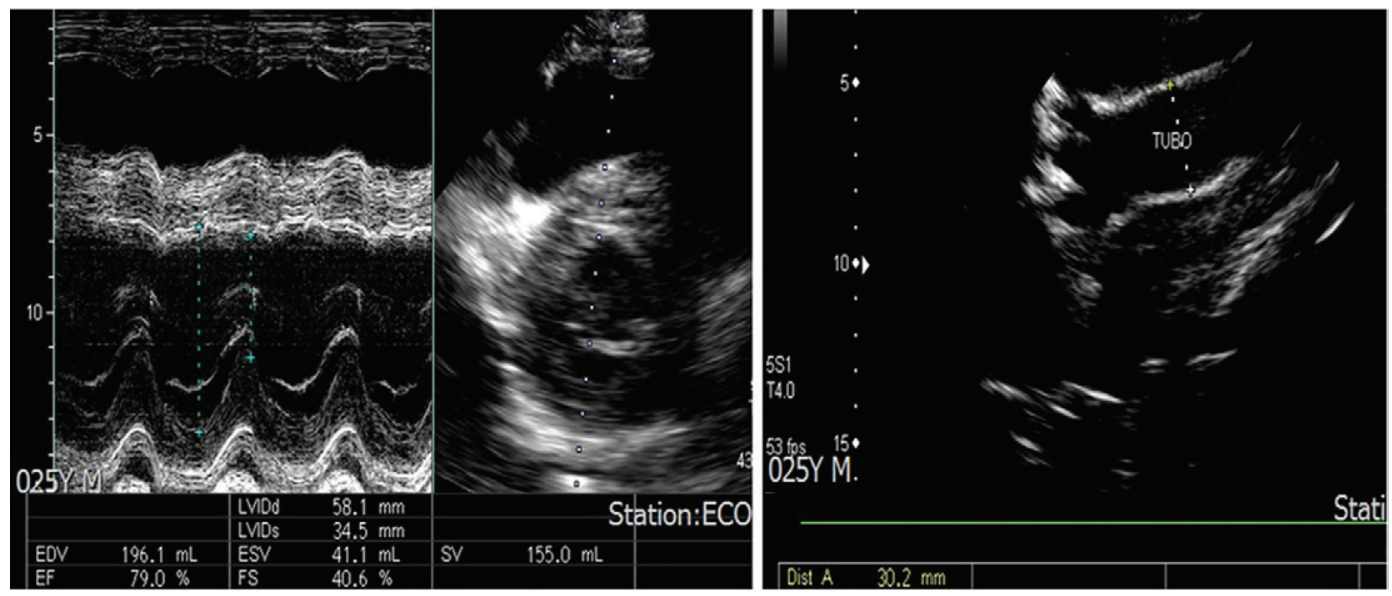

Figure 2. Doppler echocardiogram post-surgery. 


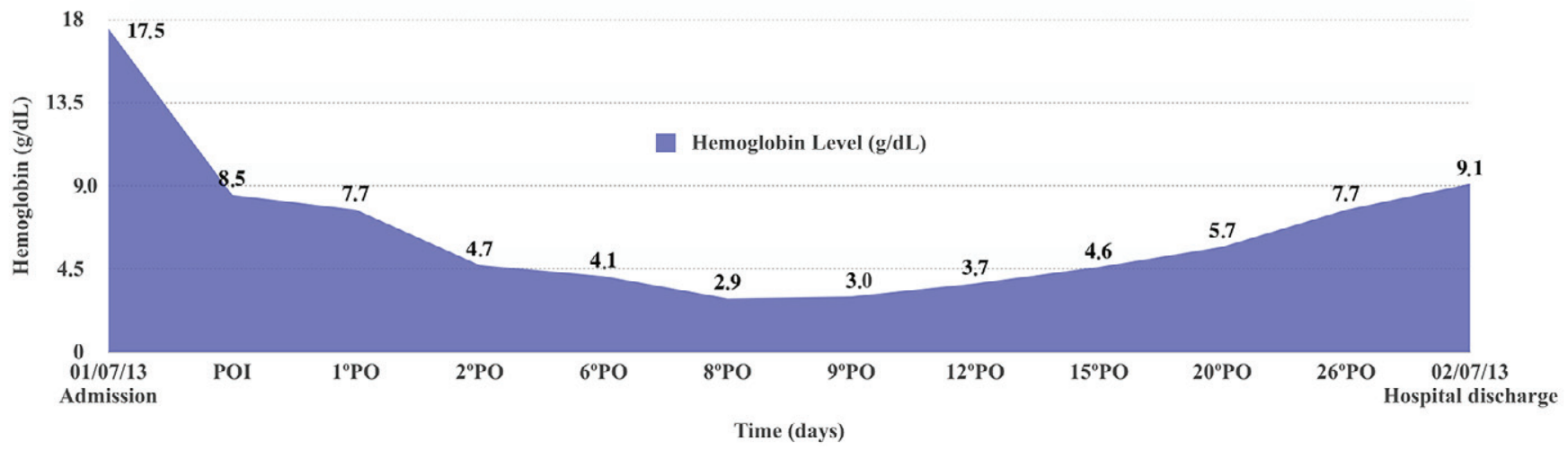

Figure 3. Hemoglobin level during hospitalization.

recombinant factor VIIa. We maintained r-Hu-EPO (600 IU/ $\mathrm{kg}$ /week), intravenous iron, folic acid and vitamin B12. Postoperatively, the patient developed severe anemia reaching a nadir at least $2.9 \mathrm{~g} / \mathrm{dL}$ of $\mathrm{Hb}$, beyond major thrombocytopenia $\left(40,000 / \mathrm{mm}^{3}\right)$. For optimizing his tissue perfusion, we kept the patient under mechanical ventilation with $100 \%$ oxygen (hyperoxic ventilation). Through this strategy, his consciousness level remained preserved all the time, without signs of cerebral and/or myocardial ischemia, and normal lactic acid $(12 \mathrm{mg} /$ dL). Other complications were pneumonia, respiratory failure, atrial fibrillation and need of dialysis due to chronic nephropathy and hyperkalemia $(6.5 \mathrm{mEq} / \mathrm{L})$.

Since then, there has been progressive improvement of the overall clinical picture. He underwent Doppler echocardiogram post-surgery that showed preserved biventricular function, normal functioning aortic bioprosthesis and presence of synthetic tube in the ascending aorta (Fig. 2). Through these autologous blood management and conservation strategies, the patient showed good clinical course and was discharged 30 days after the surgery (February 07,2013 ), with $9.1 \mathrm{~g} / \mathrm{dL}$ of $\mathrm{Hb}$ (Fig. 3) and without the use of allogeneic blood.

\section{Discussion}

Blood transfusion is the infusion of foreign antigens in the recipient's circulation, resulting in multiple inflammatory and immune reactions [12]. That is one of the main explanations for adverse outcomes of this medical practice.

Cardiac surgery is responsible for great blood products consumption at the blood banks. Studies have shown that the higher the CPB time the higher is the blood loss and the need for transfusions [9]. Before a complex and severe cardiac surgery with prolonged CPB time, with the risk of excessive bleeding, and the patient's preset position to avoid allogeneic blood, a multidisciplinary planning was necessary to develop a specific protocol for this case. This protocol involved optimizing the most the red cell mass (pre- and postoperatively), minimizing blood loss, and strategies for improving tolerance to anemia (intra- and postoperatively). The literature shows that when blood transfusion is not an option, the use of multiple modalities of blood preservation has a synergistic effect to al- leviate the use of blood products $[9-11,13]$.

Initially, a minimum $\mathrm{Hb}$ of $15 \mathrm{~g} / \mathrm{dL}$ was set to be reached at the final of the pre-operative period. As he was already using 4,000 IU of r-Hu-EPO three times a week and his $\mathrm{Hb}$ was between 12 and $13 \mathrm{~g} / \mathrm{dL}$, the strategy used to achieve the recommended goal was the use of r-Hu-EPO at a dosage of $600 \mathrm{IU} / \mathrm{kg} /$ week, beyond ferric hydroxide saccharate, folic acid, and vitamin B12. While this dose of r-HuEPO is above the standard proposed by current guideline [14] for the treatment of anemia in patients with chronic kidney disease, the severity and urgency to achieve in the shortest possible time the predetermined level of $\mathrm{Hb}$ to perform surgery made us to use this more aggressive therapy r-Hu-EPO for a period of 9 weeks.

The literature demonstrates several erythropoietin dosing regimens and duration treatment to increase red cell mass and reduce allogeneic blood transfusions. In a randomized controlled study, it was demonstrated that daily administration of $300 \mathrm{IU} / \mathrm{kg}$ of r-Hu-EPO for 5 days, and then in alternate days for at least 2 weeks significantly reduced the blood transfusions rate [15]. In critically ill patients, subcutaneous administration of 40,000 IU/week of r-Hu-EPO for a period of 4 weeks resulted in a significant increase in $\mathrm{Hb}$ level [16]. If the cause of ineffective treatment with $\mathrm{r}-\mathrm{Hu}-\mathrm{EPO}$ can be identified and corrected, higher doses can be considered (150 - $300 \mathrm{IU} / \mathrm{kg}$ at intervals of $24-72 \mathrm{~h}$ ) [17].

To reduce blood loss in this patient, we used procedures, techniques and medications to reduce the use of homologous blood in surgeries. Firstly, acute normovolemic hemodilution was performed, which is proven to reduce the use of blood and blood products [11]. Another key strategy was the intraoperative use of the blood cell salvage machine, which, in this particular case, was able to recover at least $2,100 \mathrm{~mL}$ of total blood. This therapeutic approach is recommended by the autologous blood conservation guidelines in surgeries [10].

The main surgical strategy to minimize blood loss was to provide a meticulous hemostasis, with quick and extremely careful control of bleeding, beyond the moderate hypothermia $\left(28^{\circ} \mathrm{C}\right)$ and a controlled hypotensive anesthesia with perfusion pressure of 55 - $60 \mathrm{~mm} \mathrm{Hg}$ [11].

Studies demonstrate the effectiveness of the human fibrinogen concentrate [18] and the recombinant factor VIIa [19] 
for controlling greater bleeding during surgery, and thereby, avoiding transfusions of plasma and/or platelets. In our case, these medications also proved to be effective hemostatic for controlling bleeding and avoiding the use of hemotransfusions.

Although current studies [20] would recommend treating this level of anemia with a blood transfusion, our team decided to consider the patient as a whole rather than to concentrate on the laboratory value of $2.9 \mathrm{~g} / \mathrm{dL} \mathrm{Hb}$ itself, maintaining a restrictive conduct for transfusion. First by respecting the patient's autonomy, and on the other hand, even with this very low amount of $\mathrm{Hb}$, he still remained with no signs of tissue hypoxia.

The literature reports several other cases of extreme tolerance to anemia. In one of these cases, effective strategy used to ensure tissue oxygenation even with hemoglobin as low as $1.4 \mathrm{~g} / \mathrm{dL}$ was the mechanical ventilation with elevated oxygen blood pressure [21]. In our case, we have also improved tolerance to anemia by increasing the arterial content of oxygen through hyperoxic ventilation ( $100 \%$ oxygen). The patient with $2.9 \mathrm{~g} / \mathrm{dL} \mathrm{Hb}$ remained without signs of cerebral and myocardial ischemia. While the normovolemia is maintained by the use of $100 \%$ oxygen ventilation, the appropriate systemic oxygenation can still occur in the patient with severe anemia.

The importance of these strategies to minimize the use of blood is not restricted to the economic sphere and the reduction of consumption of blood and blood products, but especially because of the incidence of adverse effects associated to the transfusion practice.

When it has the intention and/or the multidisciplinary desire for managing and conserving the autologous blood, it is possible to perform complex and serious cardiac surgeries, as exemplified by this case, without the use of hemotransfusions. This is the first case described in the literature of a patient in the postoperative period of severe and complex heart surgery, and with pneumonia, respiratory failure, atrial fibrillation, thrombocytopenia, chronic renal failure requiring dialysis and severe anemia of $2.9 \mathrm{~g} / \mathrm{dL} \mathrm{Hb}$, who survived without the use of the standard treatment of anemia with allogeneic blood transfusion.

\section{Conclusion}

A multidisciplinary planning with multiple clinical and surgical strategies to optimize red cell mass and coagulation condition, minimize blood loss, and improve tolerance to anemia with hyperoxic ventilation, was able to avoid the use of allogeneic blood in the patient with severe anemia $2.9 \mathrm{~g} / \mathrm{dL} \mathrm{Hb}$, who was submitted to severe and complex heart surgery. This case shows that it is possible to change the transfusional conduct even before a severe anemia picture and several serious associated complications.

\section{Competing Interests}

The authors have no competing interests. The authors do not hold any stock or shares in an organization that may gain or lose financially from the publication of this manuscript.

\section{References}

1. Bennett-Guerrero E, Zhao Y, O'Brien SM, Ferguson TB, Jr., Peterson ED, Gammie JS, Song HK. Variation in use of blood transfusion in coronary artery bypass graft surgery. JAMA. 2010;304(14):1568-1575.

2. Sojka BN, Sojka P. The blood donation experience: selfreported motives and obstacles for donating blood. Vox Sang. 2008;94(1):56-63.

3. Novaretti MCZ. Importancia dos carreadores de oxigenio livre de celulas. Rev Bras Hematol Hemoterapia. 2007;29(4):394-405.

4. Koch CG, Li L, Duncan AI, Mihaljevic T, Cosgrove DM, Loop FD, Starr NJ, et al. Morbidity and mortality risk associated with red blood cell and blood-component transfusion in isolated coronary artery bypass grafting. Crit Care Med. 2006;34(6):1608-1616.

5. Dornelesi CC, Bodanese LC, Guaragna JCVC et al. O impacto da hemotransfusao na morbimortalidade pos-operatoria de cirurgias cardiacas. Rev Bras Cir Cardiovasc. 2011;26(2):222-229

6. Santos AA, Sousa AG, Piotto RF, Pedroso JC. Mortality risk is dose-dependent on the number of packed red blood cell transfused after coronary artery bypass graft. Rev Bras Cir Cardiovasc. 2013;28(4):509-517.

7. LaPar DJ, Crosby IK, Ailawadi G, Ad N, Choi E, Spiess $\mathrm{BD}$, Rich JB, et al. Blood product conservation is associated with improved outcomes and reduced costs after cardiac surgery. J Thorac Cardiovasc Surg. 2013;145(3):796803; discussion 803-794.

8. Kumar A. Perioperative management of anemia: limits of blood transfusion and alternatives to it. Cleve Clin J Med. 2009;76(Suppl 4):S112-118.

9. Souza HJB, Moitinho RF. Estrategias para reducao do uso de hemoderivados em cirurgia cardiovascular. Rev Bras Cir Cardiovas. 2008;23(1):53-59.

10. Ferraris VA, Brown JR, Despotis GJ, Hammon JW, Reece TB, Saha SP, Song HK, et al. 2011 update to the Society of Thoracic Surgeons and the Society of Cardiovascular Anesthesiologists blood conservation clinical practice guidelines. Ann Thorac Surg. 2011;91(3):944-982.

11. Santos AA, Silva JP, Silva Lda F, Sousa AG, Piotto RF, Baumgratz JF. Therapeutic options to minimize allogeneic blood transfusions and their adverse effects in cardiac surgery: a systematic review. Rev Bras Cir Cardiovasc. 2014;29(4):606-621.

12. Flohe $\mathrm{S}$, Kobbe $\mathrm{P}$, Nast-Kolb D. Immunological reactions secondary to blood transfusion. Injury. 2007;38(12):14051408.

13. Goodnough LT, Shander A, Spence R. Bloodless medicine: clinical care without allogeneic blood transfusion. Transfusion. 2003;43(5):668-676.

14. Alves MAR, Gordan PA, Bevilacqua JL et al. Atualizacao da Diretriz para o Tratamento da Anemia no Paciente com Doenca Renal Cronica. J Bras Nefrol. 2014;36(1 supl):9- 
22.

15. Corwin HL, Gettinger A, Rodriguez RM, Pearl RG, Gubler KD, Enny C, Colton T, et al. Efficacy of recombinant human erythropoietin in the critically ill patient: a randomized, double-blind, placebo-controlled trial. Crit Care Med. 1999;27(11):2346-2350.

16. Corwin HL, Gettinger A, Pearl RG, Fink MP, Levy MM, Shapiro MJ, Corwin MJ, et al. Efficacy of recombinant human erythropoietin in critically ill patients: a randomized controlled trial. JAMA. 2002;288(22):28272835.

17. Eckardt KU. Anaemia of critical illness - implications for understanding and treating $\mathrm{rHuEPO}$ resistance. Nephrol Dial Transplant. 2002;17(Suppl 5):48-55.

18. Rahe-Meyer N, Hanke A, Schmidt DS, Hagl C, Pichlmaier M. Fibrinogen concentrate reduces intraoperative bleeding when used as first-line hemostatic therapy during major aortic replacement surgery: results from a randomized, placebo-controlled trial. J Thorac Cardiovasc Surg. 2013;145(3 Suppl):S178-185.

19. Lin Y, Stanworth S, Birchall J, Doree C, Hyde C. Recombinant factor VIIa for the prevention and treatment of bleeding in patients without haemophilia. Cochrane Database Syst Rev. 2011;2:CD005011.

20. Practice guidelines for perioperative blood transfusion and adjuvant therapies: an updated report by the American Society of Anesthesiologists Task Force on Perioperative Blood Transfusion and Adjuvant Therapies. Anesthesiology. 2006;105(1):198-208.

21. de Araujo Azi LM, Lopes FM, Garcia LV. Postoperative management of severe acute anemia in a Jehovah's Witness. Transfusion. 2014;54(4):1153-1157. 